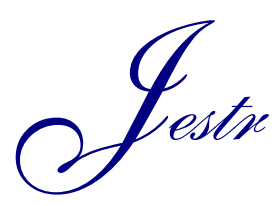

\title{
Numerical Analysis of the Influence of Ventilation at Working Face on Air Leakage in Gob
}

\author{
Tang Mingyun ${ }^{1,2, *}$, Yao Guanlin ${ }^{1,2}$, Qin Ruxiang ${ }^{1,2}$, Hu Zuxiang ${ }^{1,2}$, Duan Sanzhuang ${ }^{1,2}$ and Dai \\ Guanglong ${ }^{1,2}$ \\ ${ }^{1}$ School of Mining and Safety Engineering, Anhui University of Science and Technology, Anhui, Huainan 232001, China \\ ${ }^{2}$ Key Laboratory of Safety and High-efficiency Coal Mining, Ministry of Education, Anhui University of Science and Technology, Anhui, \\ Huainan 232001, China
}

Received 22 May 2018; Accepted 7 December 2018

\begin{abstract}
Air leakage is a key factor that leads to spontaneous combustion of residual coal in gob, and the ventilation at the working face is the direct reason for air leakage from the working face to the gob. A model of the resistance coefficient of air leakage was established based on "O"-type caving and compaction and nonlinear seepage theories to study the influence of ventilation at working face on air leakage from the working face to the gob. Computational fluid dynamics (CFD) software, Fluent, was used to simulate the flow field of the air leakage at the experimental working face with a high drainage roadway. The air volumes obtained by simulation were consistent with the field-measured data at the experimental working face. On the basis of the simulation, the influences of wind resistance and air volume at the working face on air leakage were studied. Results show that reducing the wind resistance at the working face plays a positive role in controlling the air leakage volume from the working face to the gob. When the wind resistance at the working face reduces by $50 \%$, the air leakage volume reduces by $28 \%$. Meanwhile, the effects of air volumes at the working face on air leakage volume are different. A critical value of air volume at the working face is determined $\left(24.27 \mathrm{~m}^{3} / \mathrm{s}\right)$. Only when the air volume at the working face is more than the critical value can the air leakage volume from the working face to the gob be effectively decreased by reducing the air volume at the working face. This study provides guidance for the prevention and control of air leakage in gob.
\end{abstract}

Keywords: Coal spontaneous combustion, Ventilation, Numerical simulation Air leakage, Air volume, Wind resistance

\section{Introduction}

Mine fire not only affects coal production and causes considerable waste of coal resources but also leads to property losses and casualties, even major gas explosion accidents [1]. Statistics shows that more than $60 \%$ of coal mine fires were caused by spontaneous combustion of residual coal in gob in China [2-3]. A main reason for the spontaneous combustion of residual coal is air leakage from the working face to the gob [4-7]. Therefore, studying the air leakage from the working face to the gob is important for the prevention of spontaneous combustion of residual coal in gob.

Two factors cause air leakage from the working face to the gob. One is the air leakage passage in gob, which is the main internal factor, and the other is the ventilation at the working face, which is an external factor [8-10]. Hydraulic support and wind curtain are mainly used to isolate the working face and the gob. However, complete isolation between the working face and the gob is impossible due to field restrictions, which results in a certain air leakage passage between them. Full compaction is also impossible due to roof caving after mining, which results in certain air leakage passages inside the gob. Nevertheless, air leakage

*E-mail address: mytang@aust.edu.cn

ISSN: 1791-2377 @ 2018 Eastern Macedonia and Thrace Institute of Technology. All rights reserved. doi:10.25103/jestr.116.08 can be decreased by reducing the ventilation resistance at the working face on the basis of the theory of mine ventilation [11]. Two factors may be considered to reduce ventilation resistance, that is, reducing the air volume and the wind resistance at the working face. Nevertheless, the immanent relationships between the two factors and air leakage remain unclear, especially for working face with a high drainage roadway.

On this basis, a mathematical model on air leakage flow field at the working face was constructed in this study by combining numerical simulation with actual ventilation parameters at the working face. The effect of ventilation at the working face on air leakage from the working face to the gob was studied. The aim is to reveal the internal relationship between the air leakage from the working face to the gob and the ventilation at the working face.

\section{State of the art}

The air leakage from the working face to the gob has been studied by many scholars from China and other countries. Researchers have focused on the influencing factors of air leakage and the model of permeability distribution in gob. Karacan proposed a prediction method for porosity and permeability by using the theories of fractal scale and fluid flow. The approach can calculate porosity and permeability from the size distribution of broken rock material in gob. 
Porosity and permeability were obtained from image analyses of the material in gob by using the theory of a completely fragmented porous medium. The computed results were close to measured data [12]. Shao et al. presented a 3D model of the permeability distribution in gob. The relationship between the air leakage volume in gob and the air volume at working face was simulated and analyzed. High air volume at the working face leads to high air leakage volume in the gob. The width of the spontaneous combustion zone can be decreased by reducing the air volume at the working face [13]. Xu et al. studied the flow field and oxygen concentration distribution in gob under different conditions by numerical simulation. The simulation results showed that plugging the upper and lower corners of the working face can reduce the air leakage volume in gob. Furthermore, a long-plugged distance exerts a remarkable effect on air leakage [14]. Zhu et al. compared the influences of different air volumes at the working face on the "three zones" of spontaneous combustion and concluded that high air volume at the working face results in a wide oxidation zone and a deep location in gob [15]. Taraba and Michalec used commercial CFD software, Fluent, to study the oxidation process of residual coal in gob. The adopted model of permeability in gob was mainly based on "O"-type caving and compaction theory, that is, permeability and porosity were largest at the back of the working face and the boundary of the gob, whereas permeability was smallest in the central part of the gob [16]. Zhu and Liu established a permeability and porosity distribution model and qualitatively analyzed the influence of gas extraction by high drainage roadway on the easily spontaneous combustible region in gob [17]. Yang et al. took a 3D gas drainage system as an example and combined actual measurement with simulation. The air leakage in gob was studied under the 3D gas drainage system. The depth that the air leakage flow into the gob would be highly increased because of the effect of the 3D gas drainage, and the high drainage roadway could increase the air leakage volume, thereby causing the spontaneous combustion of the residual coal in the middle zone of the gob [18]. Yang and Gao adopted CFD to simulate the distribution of air leakage in gob with various permeability magnitudes. The results showed that the distributions of air leakage volume and air velocity and the three zones of spontaneous combustion vary largely under the conditions of different permeability magnitudes. As the gob permeability gradually decreased, the air leakage volume and the seepage velocity in the gob decreased, and the spontaneous combustion zone approached the working face [19]. From the perspective of 4D, which included 3D space and time dimensions, Shi et al. presented a method that could be defined as "steady mesh and variable property" to simulate the dynamic mining process at the working face. The optimized dynamic model of the porosity and permeability was used to obtain the distribution law of oxygen concentration in different periods during mining at the working face. This permeability model was also based on "O"-type circle theory and the Carman-Kozeny model [20]. Cheng et al. optimized ventilation parameters, such as the air volume at the working face, the negative pressure of gas drainage, and the allocation of air volume of high drainage roadway, by using the CFD simulation to solve the dangers in spontaneous combustion of residual coal and gas disasters in gob. The results showed that increasing the air volume and the negative pressure can decrease the gas concentration of return roadway, although it may also increase the risk of spontaneous combustion of the residual coal in gob [21]. Tang et al. studied the influence of gas drainage by high drainage roadway on air leakage in gob. The results showed that the gas drainage by high drainage roadway affected not only the air leakage volume but also the range of air leakage. The critical gas drainage volume was obtained on the basis of the relationship between gas drainage and air leakage [22]. Zhuo et al. studied the mining cracks and air leakage caused by repeated mining of shallow coal seams at Bulianta Coal Mine, Shendong Coalfield, China. A similar simulation experiment was performed in a laboratory by combining with the distribution of mininginduced cracks, and the cracks of air leakage on surface were measured. The results showed that the width of vertical fractures in the boundary area of the overlying gob increased evidently after the repeated mining of coal seams, whereas the vertical fractures in the central area of the overlying gob nearly did not change. The distribution of air leakage cracks on the surface looked like a shape of "Dual-ellipse" This result was similar to the "O"-type caving compaction distribution in gob [23].

The aforementioned literature has indicated that many scholars have analyzed the influence of air volume at the working face and gas drainage by high drainage roadway on air leakage in gob. However, the critical value of air volume at the working face with gas drainage by high drainage roadway has not been obtained, and the influence of wind resistance at the working face on the air leakage in gob has yet to be explored. In the present work, a model of the porosity and permeability in gob was established on the basis of "O"-type caving and compaction theory and the nonlinear seepage model by Bachmat. Fluent was used to simulate the flow field of air leakage in the gob at the experimental working face [24]. The simulation results were compared with the parameters obtained by the actual measurement, and the influences of air volume and wind resistance at the working face were studied. This study provides an important theoretical basis for preventing spontaneous combustion of residual coal in gob.

\section{Methodology}

\subsection{Mathematical models}

\subsubsection{Basic hypothesis}

The basic hypotheses are as follows:

(1) The pressure in the gob is small, and the airflow expansion caused by heat transfer is ignored; therefore, fluid is considered incompressible in stope [25].

(2) Gob is formed by the accumulation of caving rocks and is usually considered an isotropic porous medium [26].

\subsubsection{Basic flow equations}

The flow pattern of the working face and gob was treated as a non-Darcy flow because turbulent, laminar, and transition flows exist. A $k-\varepsilon$ turbulence model was used to simulate the airflows at the tail airway, return roadway, high drainage roadway, and working face, which were regarded as fully developed turbulent flows [27-28]. On the basis of the principle of conservation of airflow mass and momentum at the stope, the balance equations of airflow mass and momentum are obtained as follows [24,28-29]: 
Tang Mingyun, Yao Guanlin, Qin Ruxiang, Hu Zuxiang, Duan Sanzhuang and Dai Guanglong/ Journal of Engineering Science and Technology Review 11 (6) (2018) 54 - 61

$$
\left\{\begin{array}{c}
\frac{\partial(\rho)}{\partial \tau}+\frac{\partial\left(\rho u_{i}\right)}{\partial x_{i}}-q_{m}=0 \\
\frac{\partial\left(\rho u_{i}\right)}{\partial \tau}+\frac{\partial\left(\rho u_{i} u_{j}\right)}{\partial x_{i}}=-\frac{\partial p}{\partial x_{i}}+\frac{\partial \tau_{i j}}{\partial x_{j}}+\rho g_{i}+F_{i}
\end{array}\right.
$$

where $\rho$ is the fluid density $\left(\mathrm{kg} / \mathrm{m}^{3}\right), u_{i}, u_{j}$ are the air velocities of the unit body at $i$ and $j$ directions, respectively $(\mathrm{m} / \mathrm{s}), q_{m}$ is the gas emission volume $\left(\mathrm{kg} /\left(\mathrm{m}^{3} \cdot \mathrm{s}\right)\right), p$ is the static pressure $(\mathrm{Pa}), \tau_{i j}$ is the stress tensor $(\mathrm{Pa}), \rho g_{i}$ are the gravitational body force $\left(\mathrm{N} / \mathrm{m}^{3}\right), F_{i}$ is a momentum source term $\left(\mathrm{N} / \mathrm{m}^{3}\right)$. The flow pattern of air leakage in the gob consists of laminar and transition flows, and $F_{i}$ can be expressed in the gob as follows:

$$
F_{i}=-\left(\frac{\mu}{k} u_{i}+\frac{1}{2} C_{2} \cdot \rho|u| \cdot u_{i}\right)
$$

where $\mu$ is the hydrodynamic viscosity ( $\mathrm{pa} \cdot \mathrm{s}), k$ is the permeability of porous media $\left(\mathrm{m}^{2}\right)$, and $C_{2}$ is the factor of inertial resistance $(1 / \mathrm{m})$. This equation is Darcy flow if $C_{2}$ approaches 0 . The solutions of $1 / k$ and $C_{2}$ are analyzed in detail in the next section.

\subsubsection{Model of air leakage resistance coefficient in gob}

On the basis of the nonlinear equations of seepage motion in porous media by Bachmat (1965), the equations are obtained and expressed as follows [30]:

$$
-\nabla h=(a+b|V|) \vec{V}
$$

where $\mathrm{V}$ is the fluid velocity $(\mathrm{m} / \mathrm{s}), \nabla h$ is the pressure head $(\mathrm{m})$, and a and $\mathrm{b}$ are scalar coefficients and can be expressed by:

$$
\left\{\begin{array}{l}
a=v /(g \cdot k) \\
b=\beta \cdot D_{\mathrm{m}} /(g \cdot n \cdot k)
\end{array}\right.
$$

where $g$ is the acceleration of gravity $\left(\mathrm{m} / \mathrm{s}^{2}\right), n$ is the porosity, $\beta$ is the shape factor of medium particles, and $D_{\mathrm{m}}$ is the average and harmonic particle size $(\mathrm{m})$. In this study, the value of $g$ is $9.81 \mathrm{~m} / \mathrm{s}^{2}$, the value of $\beta$ is 1.5 , and the value of $D_{\mathrm{m}}$ is $0.2 \mathrm{~m}$ obtained by simulating the air leakage in the gob under different values of $D_{\mathrm{m}}$ and comparing the simulation result with the actual field data.

The functional relationship between permeability $k$ and porosity $n$ is obtained by using the Blake-Kozeny formula [31-32], that is,

$$
k=\frac{D_{\mathrm{m}}^{2}}{150} \cdot \frac{n^{3}}{(1-n)^{2}}
$$

The porosity can be obtained by the coefficient of the bulk increase in caving rocks in the gob that is shown as $K_{\mathrm{p}}$ and can be expressed by:

$$
n(x, y)=1-1 / K_{\mathrm{p}}(x, y)
$$

On the basis of the general law of mine pressure, coefficient $K_{\mathrm{p}}$ can be obtained by the law of attenuation of the negative exponent [25], that is,

$$
K_{\mathrm{p}}(x, y)=K_{\mathrm{p}}^{\prime}+\left(K_{\mathrm{p}}^{0}-K_{\mathrm{p}}^{\prime}\right) \cdot \exp (-a \cdot d)
$$

where $K_{\mathrm{p}}^{0}$ is the initial coefficient of the bulk increase in caving, $K_{\mathrm{p}}^{\prime}$ is the coefficient of the bulk increase after compacting, $a$ is the decay rate $\left(\mathrm{m}^{-1}\right)$, and $d$ is the distance from the coordinate in the gob to the boundary $(\mathrm{m})$. In this study, the value of $K_{\mathrm{p}}^{0}$ is 1.45 , and the value of $K_{\mathrm{p}}^{\prime}$ is 1.15 . Thus, the distribution of these coefficients depends on the blackness and intensity of the rock in the caving zone. The compaction degrees in the gob behind the working face and in the deep gob are significantly different because the compaction degree of caving rocks is related not only to the carving time but also to the mine pressure. In this study, the decay rate is 0.037 in the gob behind the working face and 0.268 in the deep gob.

From Eq. 2, the viscous resistance coefficient $C_{1}$ and the inertial resistance coefficient $C_{2}$ in Fluent are calculated as follows:

$$
\left\{\begin{array}{l}
C_{1}=\frac{1}{\mathrm{k}} \\
C_{2}=\frac{2 \cdot \beta \cdot \mathrm{D}_{\mathrm{m}}}{\mathrm{k} \cdot \mathrm{n}}
\end{array}\right.
$$

A user-defined function was used to compile and achieve the solution [24].

\subsubsection{Pressure difference of air leakage in gob}

The structure of ventilation network shows that the branch of air leakage in the gob is parallel to the branch of ventilation at the working face. Their relationship in the structure of the ventilation network is shown in Fig. 1. The figure shows that a main reason for air leakage in gob is the ventilation resistance at the working face. On the basis of the theory of mine ventilation [11,33], ventilation resistance at the working face depends on the air volume at the working face and the wind resistance at the working face. The ventilation resistance is expressed as follows:

$$
H_{\mathrm{R}}=R \cdot Q^{2}
$$

where $H_{\mathrm{R}}$ is the ventilation resistance at the working face (Pa), $Q$ is the air volume at the working face $\left(\mathrm{m}^{3} / \mathrm{s}\right), R$ is the wind resistance at the working face $\left(\mathrm{kg} / \mathrm{m}^{7}\right)$, and $R$ can be calculated as

$$
R=\alpha \cdot \frac{L \cdot U}{S^{3}}
$$

where $L$ is the length of the working face $(\mathrm{m}), S$ is the section area of the working face $\left(\mathrm{m}^{2}\right)$, and $\alpha$ is the ventilation resistance coefficient $\left(\mathrm{kg} / \mathrm{m}^{3}\right)$. The ventilation 
resistance coefficient is mainly related to the support type and condition of the roadway.

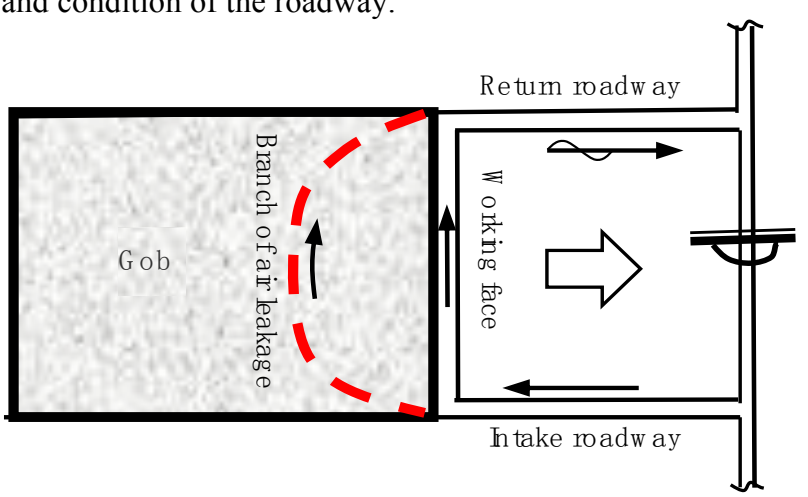

Fig. 1. Schematic of air leakage in gob

\subsection{Simulation of the flow field of working face and gob}

\subsubsection{Physical model}

The Kouzidong Coal Mine is located in the southeast of China. The working face belongs to 13-1 coal seam of the Kouzidong Coal Mine. The No. 13-1 coal seam is at risk of spontaneous combustion and explosibility. The gas in the gob is extracted by high drainage roadway. The volume flow of extraction $q$ is $1.5-2.17 \mathrm{~m}^{3} / \mathrm{s}$. The negative pressure of high drainage roadway is $2.4 \mathrm{kPa}$. The volume flow rate of the high drainage roadway is set to $1.67 \mathrm{~m}^{3} / \mathrm{s}$ in this study. The gas emission volume in the gob is $0.3032 \mathrm{~m}^{3} / \mathrm{s}$, which is treated as quality source and is set to $1.5737 \times 10^{-7}$ $\mathrm{kg} /\left(\mathrm{m}^{3} \cdot \mathrm{s}\right)$ in the $3 \mathrm{D}$ modeling. The ventilation system of the working face is U-style ventilation, and the air volume is $40.0 \mathrm{~m}^{3} / \mathrm{s}$. On the basis of the condition of the actual arrangement of the high drainage roadway, the vertical distance between the high drainage roadway and the floor is $35 \mathrm{~m}$, and the horizontal distance between the high drainage roadway and the return roadway is $39 \mathrm{~m}$. The angles of the caving and fracture are $60^{\circ}$. The total height of the caving and fracture zone is $44.5 \mathrm{~m}$. Table 1 shows the parameters of the working face stope model, and the 3D model of the stope is shown in Fig. 2.

The ventilation resistance of the working face is $96.0 \mathrm{~Pa}$ on the basis of the data measured from field. The wind resistance of the working face is $0.06 \mathrm{~kg} / \mathrm{m}^{7}$, which is obtained by Eq. 9. The ventilation resistance coefficient is set to $0.06534 \mathrm{~kg} / \mathrm{m}^{3}$ on the basis of Eq. 10 .

Table 1. Parameter list of the 111304 stope model

\begin{tabular}{llll}
\hline Roadway & $\begin{array}{l}\text { Length } \\
(\mathbf{m})\end{array}$ & $\begin{array}{l}\text { Width } \\
(\mathbf{m})\end{array}$ & Height (m) \\
\hline Intake roadway & 20 & 4 & 4.5 \\
Return roadway & 20 & 4 & 4.5 \\
High drainage roadway & 24.6 & 4 & 3.6 \\
Working face & 315 & 4 & 4.5 \\
Gob & 200 & 315 & 44.5 \\
\hline
\end{tabular}

\subsubsection{Boundary conditions}

The interfaces between the gob and working face, between the gob and high drainage roadway, between the working face and intake roadway, and between the working face and return roadway were set to interior. The inlet of the intake roadway was set to the velocity inlet. The outlets of high drainage and return roadways were set to outflow. Other boundaries were set to walls [34].

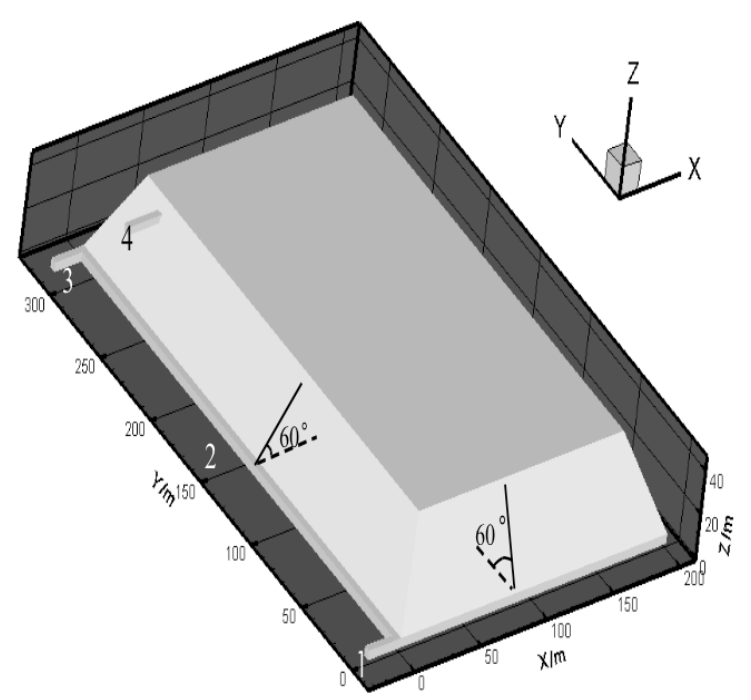

1-Intake roadway, 2-Working face, 3-Return roadway, 4-High drainage roadway

Fig. 2. Schematic of the 111304 stope model

\subsubsection{Basic approach to numerical model}

The commercial CFD software Fluent (version 14.0) was used to solve the numerical model. Mesh generator software GAMBIT was used to create the cell grid for the simulation. In the gob, the meshes in the zones of $0-25 \mathrm{~m}$ and $175-200$ $\mathrm{m}$ behind the working face were tetrahedron grids. In the middle of the gob, the grids were hexahedral grids with a size of $1.5 \mathrm{~m}$ in the zone of $25-175 \mathrm{~m}$ behind the working face. The meshes in the other zones were hexahedral, and the size of the meshes was $1 \mathrm{~m}$ in the gob of $25-175 \mathrm{~m}$ because of the small velocity gradient.

The mass and momentum equations must be solved. Pressure and velocity were coupled. The discretization scheme of the governing equation was set to first-order upwind scheme. The pressure-velocity coupling was solved by SIMPLE solver.

\section{Simulation result and analysis}

\subsection{Comparison and analysis of simulation and measured results}

The simulation result must agree with the actual field data. Therefore, the obtained results by simulation, such as the distribution tendency of air volume at the working face, the ventilation resistance at the working face, and the negative pressure of gas extraction of high drainage roadway, were compared with the parameters in the actual field.

The air volumes at different places of the working face were measured by professional staff; hence, the distribution of air volumes at the working face was obtained. The measuring site was selected in Working Face 111304 of the Kouzidong Coal Mine, and 23 measuring points were arranged at different distances from the lower corner of the working face. The professional staff used a wind meter to measure the air volumes at Working Face 111304. The measurement was implemented during the shutdown and maintenance of working face equipment to ensure the safety and accuracy of the measurement process. The measurement was conducted by only one staff member to ensure the safety and reduce artificial error. A comparison of air volume at the working face between the actual measurement and the 
Tang Mingyun, Yao Guanlin, Qin Ruxiang, Hu Zuxiang, Duan Sanzhuang and Dai Guanglong/

Journal of Engineering Science and Technology Review 11 (6) (2018) 54 - 61

simulation is shown in Fig. 3. The results of the simulation and actual measurement were consistent.

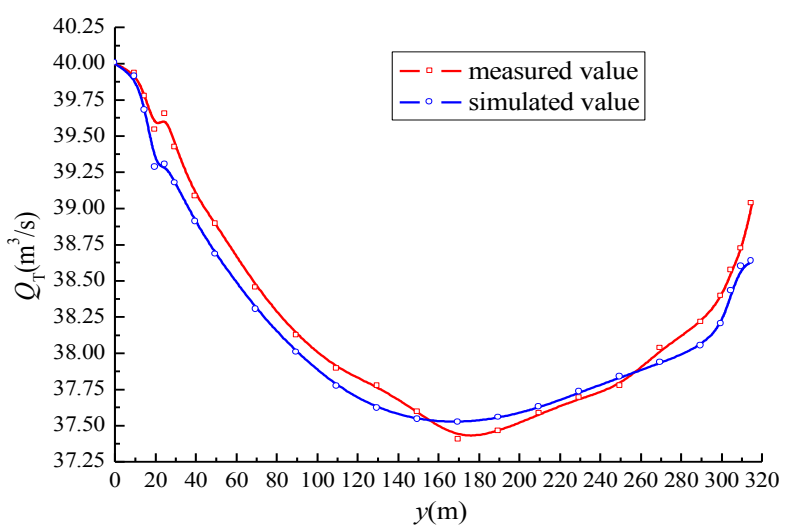

Fig. 3. Comparison of air volume at the working face between the actua measurement and simulation

The profiles of $\mathrm{z}=2 \mathrm{~m}$ and $\mathrm{y}=274 \mathrm{~m}$ were selected on the basis of the model size to show the air velocity and pressure field of the working face, high drainage roadway, and gob to observe roundly the pressures and air velocity. The air velocity and pressure field distributions are shown in Figs. 4 and 5, respectively.

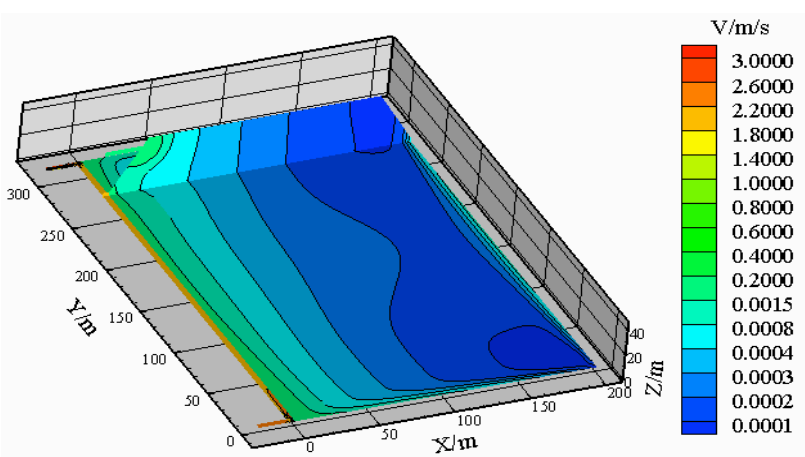

Fig. 4. Air velocity distribution at the profile of $z=2 \mathrm{~m}$ and $\mathrm{y}=274 \mathrm{~m}$

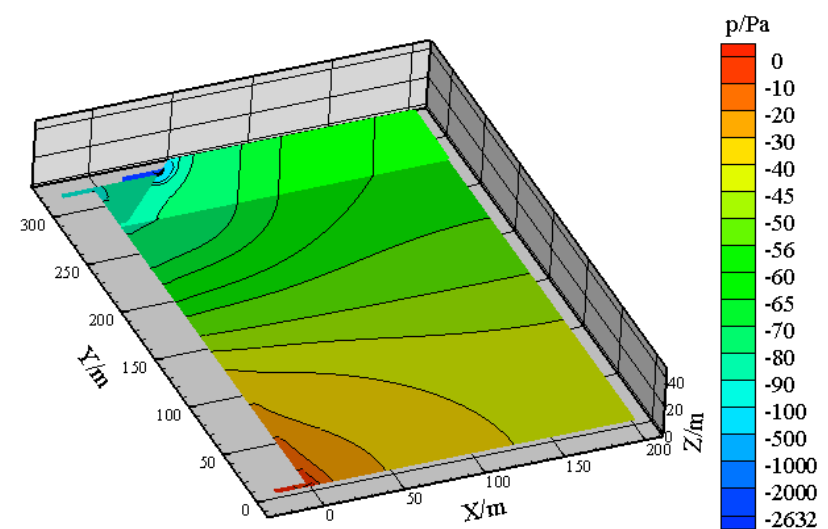

Fig. 5. Pressure distribution at the profile of $\mathrm{z}=2 \mathrm{~m}$ and $\mathrm{y}=274 \mathrm{~m}$

As shown in Fig. 4, the airflow is mainly in the intake roadway, return roadway, and working face. In the gob, a high airflow velocity occurs near the working face and gob boundary. The central section of the gob is the compaction zone; thus, the airflow velocity is the smallest. The airflow velocity around the drainage roadway is large because of the gas extraction by the drainage roadway. As shown in Fig. 5, the pressure of the side of intake air is larger than the pressure of the side of return air. The pressure around the high drainage roadway is the smallest because of the gas extraction by the drainage roadway. The simulation result implies that the pressure of the high drainage roadway is $-2.6 \mathrm{kPa}$, which is consistent with the actual pressure of the high drainage roadway, that is, $-2.4 \mathrm{kPa}$. The pressure difference between the intake and return roadways obtained by simulation is $99.0 \mathrm{~Pa}$, which is also in accordance with that obtained by actual field measurement.

\subsection{Influence of air volume at working face on air leakage}

The influence of the air volume at the working face on air leakage in the gob was studied with different air volumes. The volumes were 10, 20, 24.27, 30, 40, 50, and $60 \mathrm{~m}^{3} / \mathrm{s}$. The distributions of air volume flow rates at the working face are shown in Fig. 6.

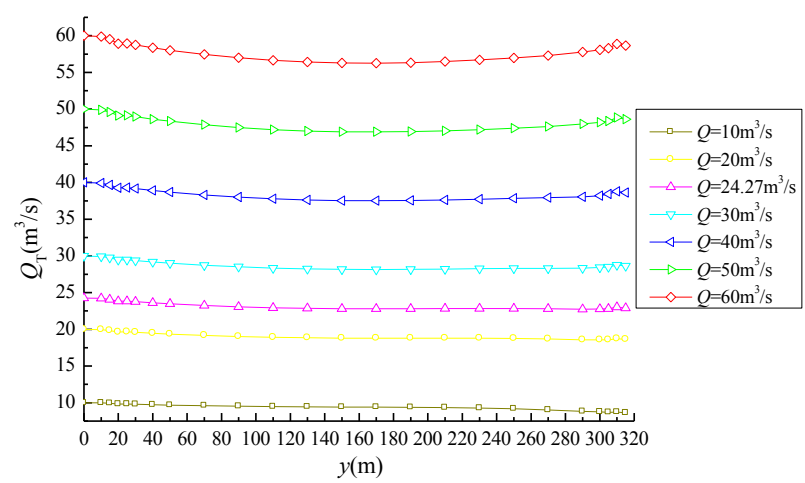

Fig. 6. Comparison graph of air volume on working face tendency under different air volumes

Fig. 6 shows that the distributions of air volume at the working face are different. When the air volumes at the working face are $30.00,40.00,50.00$, and $60.00 \mathrm{~m}^{3} / \mathrm{s}$, the air volume flow rate gradually decreases in the zone of 0 $170 \mathrm{~m}$ at the working face, which indicates that some of the air volume flows into the gob. The air volume is the smallest at $170 \mathrm{~m}$. Therefore, the source of the air leakage is in $0-170$ $\mathrm{m}$ on the working face. The air volume gradually increases in the region of 170-300 $\mathrm{m}$ because some of the air volume leaking into the gob flows back to the working face and the rest flows into high drainage roadway. When the air volumes at the working face are 20.00 and $24.27 \mathrm{~m}^{3} / \mathrm{s}$, the air volume initially decreases, and the air volume does not change. However, the air volume decreases all the time when the air volume at the working face is $10.00 \mathrm{~m}^{3} / \mathrm{s}$. As shown in Fig. 6, the relationship between the air leakage volume and the air volume at the working face is obtained and shown in Fig. 7.

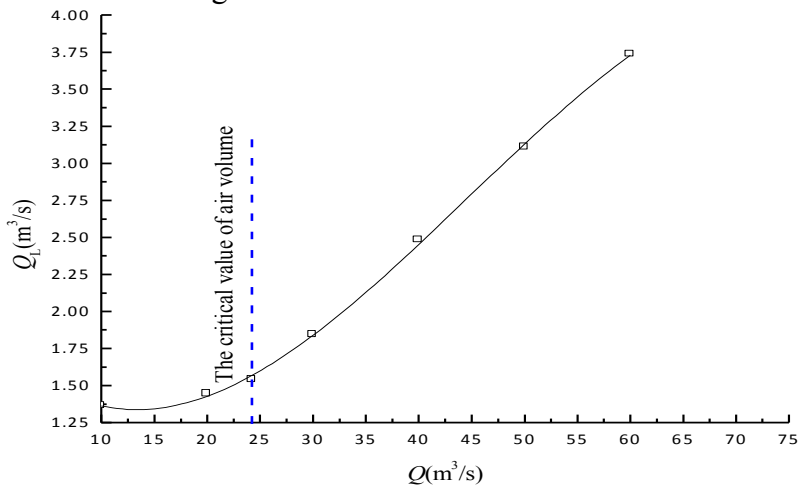

Fig. 7. Curve relationships between the air leakage volume and the air volume at the working face 
In Fig. 7, $Q_{\mathrm{L}}$ is the air leakage volume from the working face $\left(\mathrm{m}^{3} / \mathrm{s}\right)$. Fig. 7 shows that large air volume at the working face indicates large air leakage volume. The functional relationship between them is obtained by curve fitting, as shown as follows:

$$
\begin{aligned}
& Q_{\mathrm{L}}=-2.356 \cdot 10^{-5} \cdot Q^{3}+0.0031 \cdot Q^{2}-0.0711 \cdot Q+1.784 \\
& \left(10 \mathrm{~m}^{3} / \mathrm{s} \leq Q \leq 60 \mathrm{~m}^{3} / \mathrm{s}\right)
\end{aligned}
$$

Eq. 11 indicates that the relationship between air leakage volume and the air volume at the working face is a cubic polynomial function.

As shown in Fig. 7, the air leakage volume increases with the air volume at the working face. The increase in the air volume at the working face leads to the increase in the ventilation resistance of the working face. From Eq. 11, the air leakage volume is $3.73,1.36$, and $1.57 \mathrm{~m}^{3} / \mathrm{s}$ when the air volume at the working face is $60.00,10.00$, and 24.27 $\mathrm{m}^{3} / \mathrm{s}$, respectively. When the air volume decreases from $24.27 \mathrm{~m}^{3} / \mathrm{s}$ to $10 \mathrm{~m}^{3} / \mathrm{s}$ (by $58.80 \%$ ), the air leakage volume decreases from $1.57 \mathrm{~m}^{3} / \mathrm{s}$ to $1.36 \mathrm{~m}^{3} / \mathrm{s}$ (by $13.38 \%$ ). However, when the air volume decreases from 60 $\mathrm{m}^{3} / \mathrm{s}$ to $24.27 \mathrm{~m}^{3} / \mathrm{s}$ (by $59.55 \%$ ), the air leakage volume decreases from $3.73 \mathrm{~m}^{3} / \mathrm{s}$ to $1.57 \mathrm{~m}^{3} / \mathrm{s}$ (by $57.91 \%$ ). The air volume at the working face exerts a larger influence on the air leakage volume when the air volume is larger than $24.27 \mathrm{~m}^{3} / \mathrm{s}$. Therefore, the critical value of air volume at the working face is $24.27 \mathrm{~m}^{3} / \mathrm{s}$. When the air volume is $24.27 \mathrm{~m}^{3} / \mathrm{s}$, the air leakage volume is $1.36 \mathrm{~m}^{3} / \mathrm{s}$ without gas extraction of the high drainage roadway, and the gas emission volume in the gob is $0.3032 \mathrm{~m}^{3} / \mathrm{s}$. The summation of $1.36 \mathrm{~m}^{3} / \mathrm{s}$ and $0.3032 \mathrm{~m}^{3} / \mathrm{s}$ is $1.6632 \mathrm{~m}^{3} / \mathrm{s}$, which is roughly equal to the gas extraction volume of the high drainage roadway $\left(1.67 \mathrm{~m}^{3} / \mathrm{s}\right)$.

The preceding analysis indicates that reducing the air volume at the working face can reduce the air leakage volume from the working face to the gob. The air volume should be controlled on the premise of safety under the precondition that the mining can be performed normally. However, when the air volume at the working face is smaller than the critical value, reducing the air volume exerts a small effect on air leakage because of gas drainage by high drainage roadway.

\subsection{Influence of wind resistance at working face on air leakage}

Hydraulic supports exist at a fully mechanized face, with a minimum value of ventilation resistance coefficient. The minimum value of ventilation resistance coefficient of a fully mechanized coal mining face is $0.022 \mathrm{~kg} / \mathrm{m}^{3}$ according to Literature 11. On the basis of Eq. 10 and Table 1 , the minimum wind resistance can be calculated to be $0.0202 \mathrm{~kg} / \mathrm{m}^{7}$. Different wind resistances at the working face were simulated to study the influences of the different wind resistances at the working face on air leakage. The wind resistances were 0.0202, 0.0293, 0.0394, 0.0495,
$0.0597,0.0698$, and $0.0794 \mathrm{~kg} / \mathrm{m}^{7}$. The simulations were compared and analyzed. The distributions of air volume at the working face under different wind resistances were obtained on the basis of the simulation results, as shown in Fig. 8.

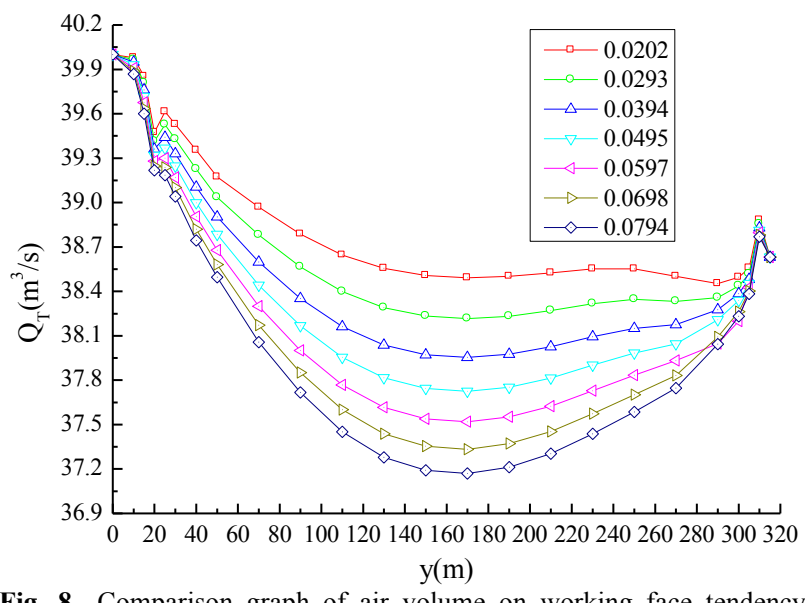

Fig. 8. Comparison graph of air volume on working face tendency under different wind resistance values

Fig. 8 shows that the distribution of the air volume at the working face is a "U"-type distribution, and the distribution law of the air leakage is similar. However, the air leakage volumes are different. When the wind resistance is 0.0794 $\mathrm{kg} / \mathrm{m}^{7}$, the air leakage volume is largest. When the wind resistance is $0.0202 \mathrm{~kg} / \mathrm{m}^{7}$, the air leakage volume is smallest. This result indicates that reducing wind resistance can positively control the air leakage in the gob. The distribution curve of the air leakage volume under different wind resistance values is shown in Fig. 9.

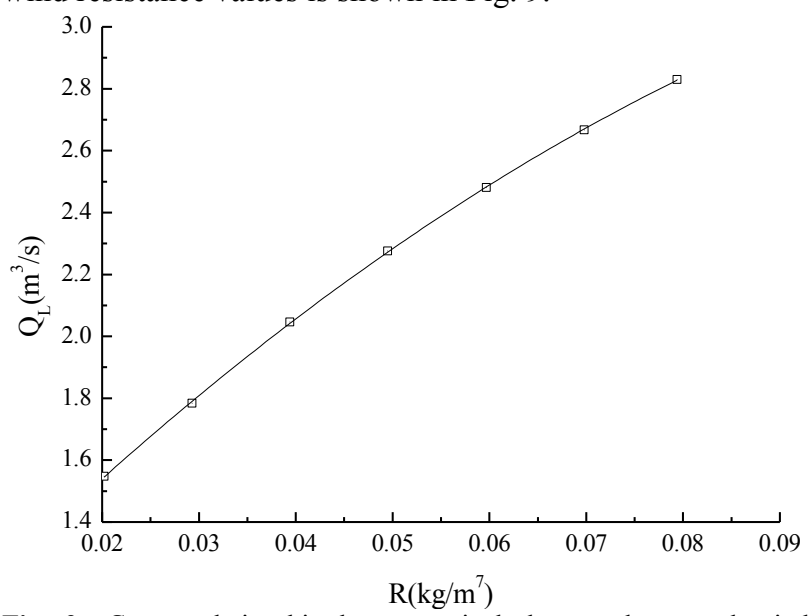

Fig. 9. Curve relationship between air leakage volume and wind resistance at the working face

Fig. 9 shows that a large value of wind resistance at the working face results in large air leakage volume. The functional relationship between them is obtained by curve fitting, as shown as follows:

$$
Q_{\mathrm{L}}=0.939+32.141 \cdot R-105.201 \cdot R^{2} \quad(0.0202 \leq R \leq 0.0794)
$$

Eq. 12 shows that the relationship between air leakage volume and the wind resistance at the working face is a quadratic polynomial function. When the wind resistance decreases by $50 \%$ (from $0.07 \mathrm{~kg} / \mathrm{m}^{7}$ to $0.035 \mathrm{~kg} / \mathrm{m}^{7}$ ), the 
air leakage volume decreases by $27.6 \%$ (from $2.67 \mathrm{~m}^{3} / \mathrm{s}$ to $1.94 \mathrm{~m}^{3} / \mathrm{s}$ ). In comparison with the influence of air volume, the influence of wind resistance is relatively smaller when the air volume at the working face is larger than the critical value. By contrast, the influence of wind resistance is relatively larger when the air volume at the working face is smaller than the critical value. At this time, the gas extraction of the high drainage roadway determines the air leakage volume.

The preceding analysis implies that reducing air resistance at the working face by controlling the length of the working face, clearing unnecessary sundries, and increasing the section area of the working face are beneficial for reducing air leakage volume from the working face to the gob.

\section{Conclusions}

To study the influence of ventilation at working face on the air leakage from the working face to the gob, the flow field of air leakage in the gob at the experimental working face was simulated and analyzed on the basis of "O"-type caving and compaction and nonlinear seepage theories. The following conclusions were obtained.

(1) The critical value of air volume is obtained as 24.27 $\mathrm{m}^{3} / \mathrm{s}$ by studying the influence of the air volume at the experimental working face on the air leakage from the working face to the gob. When the actual air volume of the working face is larger than the critical value, air leakage volume increases obviously with the air volume of the working face. Otherwise, the air leakage volume does not change with the increase in air volume of the working face.

(2) Reducing the wind resistance at the working face can effectively reduce the air leakage volume from the working face to the gob. When the wind resistance at the working face decreases by $50 \%$, the air leakage volume reduces by $28 \%$.

(3) The relationship between air leakage volume and the air volume at the working face presents a cubic function, whereas that between air leakage volume and the wind resistance at the working face shows a quadratic function.

The flow field of air leakage is complicated, which is not only affected by the geological conditions of coal seam but also closely relates to the mining conditions of the working face. Thus, the air leakage in the gob is affected by many factors, and the flow field in the gob must be further studied. The influences of surrounding rock stress, the lithology of roof and floor rocks, and the mining speed of working face should be considered in the future.

\section{Acknowledgements}

This work was supported by the National Key R\&D Program of China (NO. 2018YFC0807900), the National Natural Science Foundation of China (NO. 51774014, 51574009, 51874007), China Postdoctoral Science Foundation funded project (NO. 2016M592034).

This is an Open Access article distributed under the terms of the Creative Commons Attribution License

\section{References}

1. Lu, Y., Qin, B. T., "Identification and control of spontaneous combustion of coal pillars: a case study in the Qianyingzi Mine, China”. Natural Hazards, 75(3), 2015, pp. 2683-2697.

2. Qin, Y. P., Li, W., Yang, C., Fan, Z. Z., Wang, L. L., Jia, G. W., "Experimental study on oxygen consumption rate of residual coal in goaf'. Safety Science, 50(4), 2012, pp. 787-791.

3. Li, L., Qin, B. T., Ma, D., Zhuo, H., Liang, H. J., Gao, A., "Unique spatial methane distribution caused by spontaneous coal combustion in coal mine goafs: An experimental study". Process Safety and Environmental Protection, 116, 2018, pp. 199-207.

4. Wu, J. J., Liu, X.C., "Risk assessment of underground coal fire development at regional scale". International Journal of Coal Geology, 86(1), 2011, pp. 87-94.

5. Qin, B. T., Lu, Y., "Experimental research on inorganic solidified foam for sealing air leakage in coal mines". International. Journal of Mining Science Technology, 23(1), 2013, pp. 151-155.

6. Yang, Y. L., Li, Z. H., Tang, Y. B., Liu, Z., Ji, H. J., "Fine coal covering for preventing spontaneous combustion of coal pile". Natural Hazards, 74(2), 2014, pp. 603-622.

7. Song, Z. Y., Zhu, H. Q., Tan, B., Wang, H. Y., Qin, X. F., "Numerical study on effects of air leakages from abandoned galleries on hill-side coal fires". Fire Safety Journal, 69, 2014, pp. 99-110.

8. He, X. G., Zhang, R. W., Pei, X. D., Sun, Y., Tong, B. G., Huang, H. S., "Numerical simulation for determining three zones in the goaf at a fully-mechanized coal face". Journal of China University of Mining \& Technology, 18(2), 2008, pp. 199-203.

9. Karacan, C. Ö., Esterhuixen, G. S., Schatzel, S. J., Diamond, W. P., "Reservoir simulation-based modeling for characterizing longwall methane emissions and gob gas venthole production". International Journal Coal Geology, 71(2-3), 2007, pp. 225-245.

10. Xia, T. Q., Zhou, F. B., Gao, F., Kang, J. H., Liu, J. S., Wang, J. G., "Simulation of coal self-heating processes in underground methanerich coal seams". International Journal of Coal Geology, 141, 2015, pp. $1-12$.
11. Zhang, G.S., "The Mine Ventilation \& Safety". Xuzhou: China University of Mining and Technology press, China, 2000, pp. 3750 .

12. Karacan, C. Ö., "Prediction of Porosity and Permeability of Caved Zone in Longwall Gobs". Transport in Porous Media, 82(2), 2010, pp. 413-439.

13. Shao, H., Jiang, S. G., Wang, L. Y., Wu, Z. Y., "Bulking factor of the strata overlying the gob and a three-dimensional numerical simulation of the air leakage flow field". Mining Science and Technollgy, 21(2), 2011, pp. 261-266.

14. Xu, J. H., Liu, J., XU, J. H., "Numerical simulation research on gob air leakage of shallow buried thin bedrock thick coal seam with fully mechanized top coal caving technology". Journal of China Coal Society, 36(3), 2011, pp. 435-441 (In Chinese).

15. Zhu, Y. H., Tang, M. Y., Xia, S. B., "Numerical simulation of distribution of spontaneous combustion 'Three Zones' division in fully mechanized goaf under complicated situation". Science Technology Review, 29(12), 2011, pp. 67-70 (In Chinese).

16. Taraba, B., Michalec, Z., "Effect of longwall face advance rate on spontaneous heating process in the gob area-CFD modeling". Fuel, 90(8), 2011, pp. 2790-2797.

17. Zhu, H. Q., Liu, X. K., "Theoretical investigation on the relationship between tail roadway methane drainage and distribution of easily spontaneous combustible region in gob". Safety Science, 50(4), 2012, pp. 618-623.

18. Yang, S. Q., Zhang, M. Y., Wang, D. Q., "Study on goaf air leakage measurement and modeling of 3D gas drainage system". Coal Science Technology, 41(3), 2013, pp. 63-65 (in Chinese).

19. Yang, M., Gao, J. L., "Numerical simulation on the influence of gob permeability on distribution of air leakage flow field". International Journal of Computational Science and Engineering, 9(1-2), 2014, pp. 147-152. 
Tang Mingyun, Yao Guanlin, Qin Ruxiang, Hu Zuxiang, Duan Sanzhuang and Dai Guanglong/

Journal of Engineering Science and Technology Review 11 (6) (2018) 54 - 61

20. Shi, G. Q., Hu, F. K., Wang, D. M., Wang, S. L., "Unsteady simulation on distribution of three zones for spontaneous combustion in goaf areas". Journal of China University of Mining \& Technology, 43(2), 2014, pp. 189-194 (In Chinese).

21. Cheng, J. W., Li, S. Y., Zhang, F. X., Zhao, C. C., Yang, S. Q., Ghosh, A., "CFD modelling of ventilation optimization for improving mine safety in longwall working faces". Journal of Loss Prevention in the Process Industries, 40, 2016, pp. 285-297.

22. Tang, M. Y., Jiang, B. Y., Zhang, R. Q., Yin, Z. Q., Dai, G. L., "Numerical analysis on the influence of gas extraction on air leakage in the gob". Journal of Natural Gas Science and Engineering, 33, 2016, pp. 278-286.

23. Zhuo, H., Qin, B. T., Shi, Q. L., Li, L., "Development law of air leakage fractures in shallow coal seams: a case study in the Shendong Coalfield of China". Environmental Earth Sciences, 77, 2018, pp. 772-782.

24. ANSYS, “ANSYS FLUENT User's Guide, Release 14.0”. ANSYS Inc. 2011.

25. Li, Z. X., "CFD simulation of spontaneous coal combustion in irregular patterns of goaf with multiple points of leaking air". Journal of China University of Mining and Technology, 18(4), 2008, pp. 504-515.

26. Zhang, D. M., Liu, J. Z., "Regularity on the distribution of gas moving in gob area of coal mine". The Chinese Journal of Geological Hazard and Control, 14(1), 2003, pp. 81-84 (In Chinese).

27. Sasmito, A. P., Birgersson, E., Ly, H. C., Mujumdar, A. S., "Some approaches to improve ventilation system in underground coal mines environment - A computational fluid dynamic study". Tunnelling and Underground Space Technology, 34(1), 2013, pp. 82-95.
28. Wang, J. G., Kabir, A., Liu, J. S., Chen, Z. W., "Effects of nonDarcy flow on the performance of coal seam gas wells". International Journal of Coal Geology, 93(2), 2012, pp. 62-74.

29. Xia, T. Q., Zhou, F. B., Liu, J. S., Kang, J. H., Gao, F., “A fully coupled hydro-thermo-mechanical model for the spontaneous combustion of underground coal seams". Fuel, 125(3), 2014, pp. 106-115.

30. Di, Z. Q., Ding, G. X., Zuo, S. X., Liu, R. S., Zhao, C. C., "The theoretical calculation and observation analysis of the "Three Zones' in the goaf of fully mechanized face with top coal drawing". Journal of China University Mining Technology, 22(1), 1993, pp. 8-16 (In Chinese).

31. Luo, H. S., Quintard, M., Debenest, G., Laouafa, F., "Properties of a diffuse interface model based on a porous medium theory for solid-liquid dissolution problems". Computational Geosciences, 16(4), 2012, pp. 913-932.

32. Byon, C., Kim, S. J., "The effect of the particle size distribution and packing structure on the permeability of sintered porous wicks". International Journal of Heat and Mass Transfer, 61, 2013, pp. 499504.

33. Chatterjee, A., Zhang, L. J., Xia, X. H., "Optimization of mine ventilation fan speeds according to ventilation on demand and time of use tariff'. Applied Energy, 146, 2015, pp. 65-73.

34. Zhang, H. R., Pera, L.S., Zhao, Y.J. "Researches and applications on geostatistical simulation and laboratory modeling of mine ventilation network and gas drainage zone". Process Safety Environmental Protection, 94, 2015, pp. 55-64. 